\title{
Der verirrte Weihnachtsstern
}

Frank Seibold

Korrespondenz: Prof. Dr. med. Frank Seibold Gastroenterologie Spital Netz Bern Spital Tiefenau CH-3004 Bern Tel. 0313088942
Am 16.12.2013 stellte sich eine 55-jährige Patientin notfallmässig auf der Gastroenterologie vor. Sie klagte über heftige, krampfartige Schmerzen retrosternal. Diese Schmerzen hätten erstmals während eines Fondue-Essens begonnen und hätten sich nie ganz beruhigt. Nach dem Essen sei es immer wieder zu massiven, äusserst schmerzhaften Krämpfen gekommen. Wenige Tage zuvor war der Schwiegervater der Patientin verstorben, was dazu beitrug, dass die Patientin und ihr Ehemann das Schlimmste befürchteten. Die klinische Untersuchung auf dem Notfall und eine Blutentnahme zeigten keine Auffälligkeiten. Die Patientin wurde für eine notfallmässige Gastroskopie angemeldet.

Die Patientin wurde mit Propofol anästhesiert. Bei der Gastroskopie fand sich dann im mittleren Ösophagus ein merkwürdiger, schleimbedeckter Fremdkörper, der sich erst nach genauer Betrachtung als ein zwei Zentimeter durchmessender, golde- ner Kunststoff-Stern entpuppte. Der Fremdkörper wurde mit einer Zange gegriffen, nahe ans Gerät herangezogen und vorsichtig entfernt. Bei der anschliessenden Untersuchung fand sich keinerlei Verletzung des Ösophagus. Histologisch konnte eine eosinophile Ösophagitis (EoE) ausgeschlossen werden. Bolusobstruktionen finden sich gehäuft bei der Diagnose EoE. Hier lag offensichtlich aufgrund der Zacken des Sterns eine rein mechanische Obstruktion vor.

Woher der Stern kam, bleibt spekulativ. Es konnte rückverfolgt werden, dass das erste Schmerzereignis anlässlich des Fondue-Essens aufgetreten war, somit wäre es denkbar, dass der Stern sich eventuell in das Fonduebrot verirrt hatte. Nach der Entfernung des Sternes war die Patientin komplett beschwerdefrei und sehr erleichtert, dass das Problem so schnell behoben war.

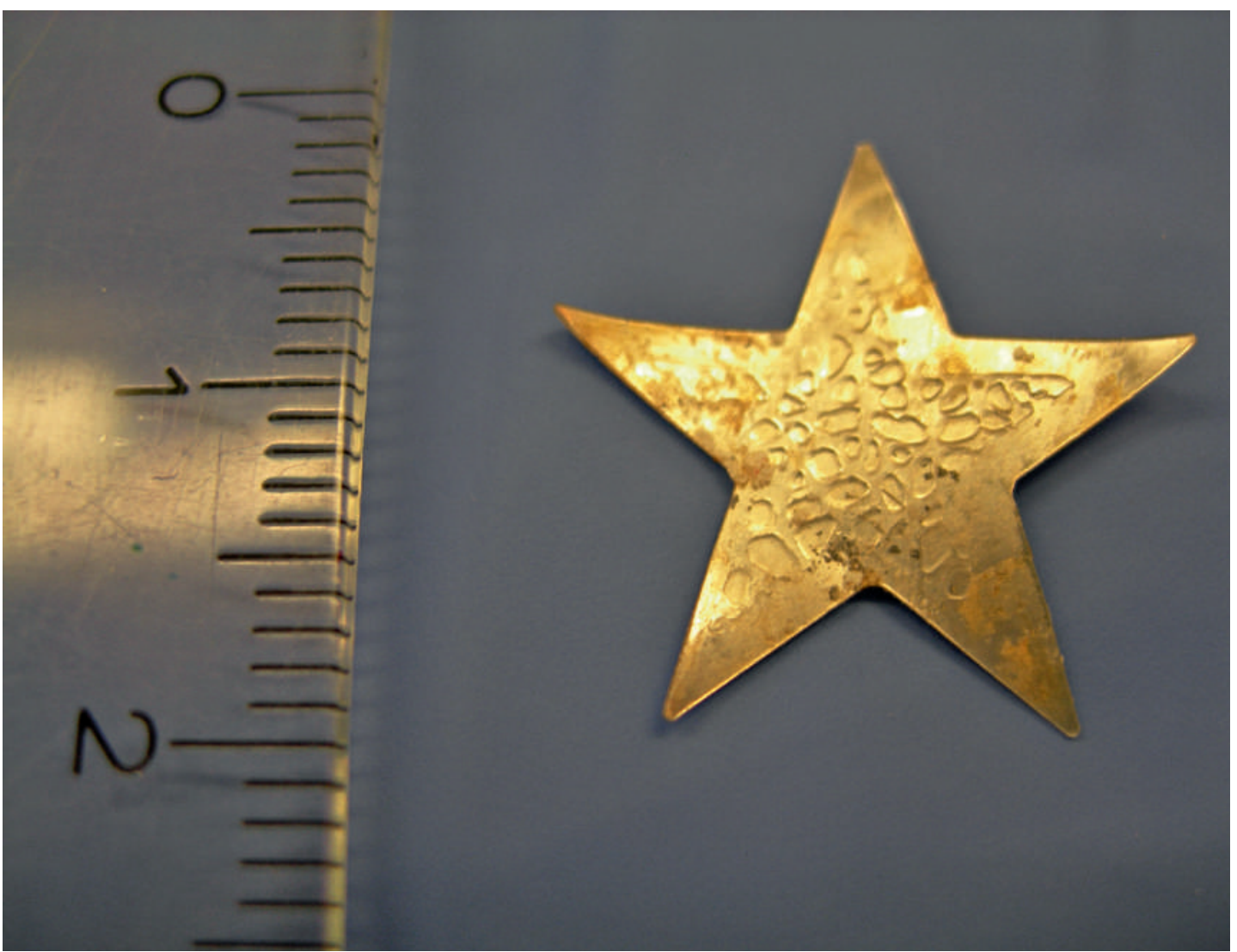

